\section{Bacterial chemical} factories

An engineered strain of the bacterium Escherichia coli can turn sugars such as glucose into a commercially important chemical.

Stephen Van Dien of Genomatica in San Diego, California, and his colleagues used computer models to design a biochemical pathway that converts common E. coli metabolites into 1,4-butanediol (BDO), which is used to make various plastics. For each step of the process, the researchers then inserted into the E. coli genes that normally encode enzymes in other bacterial species. They also tinkered with the bacterium's metabolism to drive energy and carbon molecules through this new pathway. The top-producing strain pumped out 18 grams of BDO per litre - a yield that would need to increase threeto fivefold to be commercially viable.

The bacteria could one day offer a low-cost way to make BDO from renewable products, rather than petroleum.

Nature Chem. Biol. doi:10.1038/ nchembio.580 (2011)

\section{NEUROSCIENCE}

\section{Rapid recovery from stroke}

Healthy parts of the brain can compensate for areas damaged by a stroke. Some of these changes are probably a result of the 'unmasking' of previously unused pathways rather than active rewiring.

Timothy Murphy and his colleagues at the University of British Columbia in Vancouver, Canada, induced small strokes in mice and then monitored their sensory brain activity for up to two hours while stimulating the animals' forepaws. If the stroke occurred in the right hemisphere (controlling the left paw), for example, sensory activity was higher in the left hemisphere when the left or right paw was stimulated, compared with sensory activity prior to the stroke.

Some of the changes occurred as early as 30 minutes after the stroke, too soon to have resulted from circuit rewiring. The authors suggest that stroke unleashes electrical signals that remove the inhibition that normally blocks certain existing pathways.

Proc. Natl Acad. Sci. USA doi:10.1073/pnas.1101914108 (2011)

\section{GENETICS}

\section{Genetics of malaria severity}

The mutation of just one DNA base in a gene is associated with protection against severe childhood malaria.

The FAS gene encodes a cellsurface protein called CD95, which promotes programmed cell death and has previously been implicated in severe malaria. Kathrin Schuldt at the Bernhard Nocht Institute for Tropical Medicine in Hamburg, Germany, and her colleagues looked for variants of the gene associated with severe disease in nearly 1,200 infected children in Ghana, West Africa. They found that a single nucleotide substitution in the gene's promoter - a regulatory region corresponded to increased levels of CD95 and reduced the risk of severe malaria by $29 \%$. They confirmed this finding in another 1,412 cases.

The authors speculate that boosting CD95 promotes immune-cell suicide, preventing an excessive immune response and lessening the disease's severity. PLoS Genet. 7, e1002066 (2011)

\section{PLANETARY SCIENCE}

\section{Carbon monoxide on Pluto}

Pluto's nitrogen-rich atmosphere may contain a thin layer of carbon monoxide, according to Emmanuel Lellouch at the Observatory of

COMMUNITY CHOICE

The most viewed papers in science

\title{
See-through solar cells
}

\section{HIGHLY READ \\ on apl.aip.org \\ in April} transparent to visible light.

Light striking the windows of houses and skyscrapers could one day be harvested thanks to the creation of solar cells that are

Windows typically transmit 55-90\% of visible light. Richard Lunt and Vladimir Bulovic at the Massachusetts Institute of Technology in Cambridge have developed an organic solar cell made from chloroaluminium phthalocyanine and carbon-60, which absorb ultraviolet and near-infrared light. The researchers also added near-infrared mirror coatings to boost performance. The cell's efficiency of $1.7 \%$ is comparable to that of a similar opaque cell, $2.4 \%$. The authors say that their device transmits enough visible light (55\%) to be useful for architectural glass.

Appl. Phys. Lett. 98, 113305 (2011)

Paris and his colleagues.

The surface of the dwarf planet (pictured) is known to be covered mostly by nitrogen ice, but questions remain about its atmosphere. The researchers confirmed the presence of gaseous methane and found evidence for carbon monoxide at concentrations of about $0.6 \%$ and $0.05 \%$, respectively. They observed the absorption of light that is characteristic of the molecules using a European Southern Observatory telescope in Cerro Paranal, Chile.

On the basis of modelling work, the team proposes that the carbon monoxide is concentrated either in a thin layer in Pluto's atmosphere, or, less likely, in pure patches covering $0.2-1.2 \%$ of the surface.

Astron. Astrophys. 530, L4 (2011)

Radiation's
double whammy

Radiation is known to cause cancer by damaging DNA, but may also induce other molecular changes in the surrounding tissue that accelerate tumour growth.

Mary Helen Barcellos-Hoff at the New York University

School of Medicine and her colleagues exposed mice to radiation and then inserted cancer-prone tissue into their mammary glands and those of untreated mice. One year later, tumours

had developed in all of the irradiated mice, but in only $69 \%$ of non-irradiated mice. The tumours also grew faster in the irradiated animals, and more of them were oestrogenreceptor negative, a marker of aggressive breast cancer. Furthermore, the radiation activated a protein in the surrounding tissue called TGF- $\beta$, accelerating cancer development.

The findings might help to explain why women who receive radiotherapy treatment for childhood cancer are at greater risk from early-onset breast cancer later in life.

Cancer Cell 19, 640-651 (2011)

\section{$\rightarrow$ NATURE.COM}

For the latest research published by Naturevisit:

www.nature,com/latestresearch 